\title{
AAM Special Issue of the International Conference on Structural Integrity and Durability, ICSID 2017, "Fatigue and Fracture at all Scales"
}

Received: 5 February 2019 / Accepted: 12 February 2019 / Published online: 22 February 2019

(C) Springer-Verlag GmbH Germany, part of Springer Nature 2019

The International Conference on Structural Integrity and Durability, ICSID 2017, with the subtitle "Fatigue and Fracture at all Scales" was organized by the Faculty of Mechanical Engineering and Naval Architecture, University of Zagreb, and held in Dubrovnik, Croatia, from August 15 to 18, 2017.

ICSID 2017 was held at the Centre for Advanced Academic Studies (CAAS) of the University of Zagreb, in the city of Dubrovnik in Croatia. The magnificent old building of CAAS is situated in the centre of Dubrovnik on the Croatian Adriatic Coast, in the vicinity of the most prominent historical places of the Old Town.

The objective of the ICSID 2017 conference was to bring together scientists, researchers and engineers from around the world to discuss how to analyse, predict and assess the fatigue and fracture of structural materials and components. The conference provided a forum for discussion of contemporary and future trends in experimental, analytical and numerical fracture mechanics, fatigue, failure analysis, structural integrity assessment and other important issues in the field.

Under the conference subtitle "Fatigue and Fracture at all Scales", a wide range of topics was covered such as: simulation and testing of crack propagation at all length scales; models, criteria and methods in fracture mechanics; finite element methods and their applications; macroscale fatigue prognosis techniques; effect of residual stresses; fatigue and fracture of weldments, welded components, joints and adhesives; reliability and life extension of components; corrosion, environmentally enhanced degradation and cracking, corrosion fatigue; fracture and damage of cementitious materials; fatigue and fracture of polymers, elastomers, composites and biomaterials; and others.

This special issue contains fourteen papers from the Proceedings of ICSID 2017 selected by the Guest Editors. The selected papers from the Proceedings of ICSID 2017 have been significantly extended by the authors for the AAM Special Issue ICSID 2017 and have been peer-reviewed in the usual manner. The papers present recent advances in fatigue and fracture, covering a wide range of topics from experimental methods, analytical and numerical modelling of fatigue and fracture processes, as well as fracture mechanics applications for structural integrity assessment.

As the guest editors of this special issue, we wish to thank all authors for their contributions and the reviewers who assisted in the review process. We would like to express our thanks to Professor Reinhold Kienzler, the Editor-in-Chief of the Archive of Applied Mechanics, for his generous help and support of this special issue.

Publisher's Note Springer Nature remains neutral with regard to jurisdictional claims in published maps and institutional affiliations.

\footnotetext{
Ž. Božić $(\bowtie)$

University of Zagreb, Zagreb, Croatia

E-mail: zeljko.bozic@fsb.hr

S. Schmauder

University of Stuttgart, Stuttgart, Germany
} 